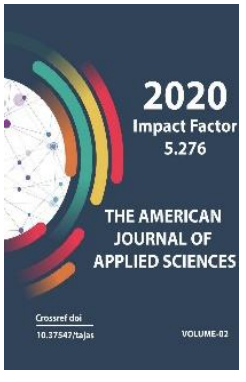

Journal Website: http://usajournalshub.c om/index,php/tajas

Copyright: Original content from this work may be used under the terms of the creative commons attributes 4.0 licence.

\section{Ecological Status Of Anthropogenic Landscapes Of Samarkand Oash}

\section{Abbasov S.B.}

Doctor Of Geographical Sciences, Professor Of Samarkand State University, Uzbekistan

Baxtiyorova D.

Master's student of Samarkand State University, Uzbekistan

Eshquvvatov B.B.

Senior Lecturer of Samarkand State University, Uzbekistan

\title{
ABSTRACT
}

This article describes the ecological condition of the landscapes of the Samarkand oasis, the factors affecting the landscapes and the preservation of landscape stability, which have their own characteristics in our country.

\section{KEYWORDS}

Oasis landscape, population, agriculture, production, environmental issues, productivity, desertification, stabilization, chemicalization, irrigation.

\section{INTRODUCTION}

The impact of anthropogenic factors on natural and cultural landscapes, which is stronger than the geological process in the modern era of scientific and technological progress, is widespread, leading to aggravation of the ecological situation and, in some regions, ecological crisis.

Today, due to the intensive use of landscapes to provide humanity with natural resources, 
man-made degradation, desertification, deterioration of land reclamation, soil erosion, degradation, deflation, desertification and other negative geo-ecological and natural geographical processes are increasing day by day. International organizations are paying great attention to combating these problems.In particular, the UN Program for Sustainable Development until 2030 sets the tasks of "protection and restoration of terrestrial ecosystems, their rational use, rational forest management, combating desertification, stopping land degradation and preventing biodiversity loss."

Preservation of the stability and ecological balance of the landscapes of the Samarkand oasis, which has its own colorful landscapes, depends primarily on factors such as technology of nature use, urbanization of the region, non-disruption of the mechanism of interconnection, full compliance with rational and purposeful use of nature.

\section{Materials And Methods}

When a person uses natural resources during his economic activity, it is desirable to have information about the external and internal relationships of geographical components, zonal and altitude relationships, the balance of matter and energy exchange in landscape systems, the biological productivity of each type of agrolandscape. Because any mistake made by man in the process of using nature has a negative impact on anthropogenic and natural landscapes, disrupts the historically formed ecological balance in them and aggravates the ecological situation.

Today, there are many definitions and concepts of landscape sustainability, and if we summarize them, we can conclude that landscape sustainability is the ability to withstand the effects of external natural or anthropogenic factors while maintaining its structure, ie the nature of internal relationships. or the ability to restore the previous state in case of damage [4].

A comprehensive study of the landscapes of the Samarkand oasis shows that in recent years, the deterioration of the functional geoecological situation in irrigated agrolandscapes, irrigation, man-made and even pasture anthropogenic geosystems, air pollution with various toxic emissions, aggravation of the environment, chemical pollution of inland waters. such as adverse events affecting human health are increasing [1].

The various sources that pollute the landscapes of the Samarkand oasis and negatively affect their ecological status are very common. Examples of such sources are agricultural chemicals, household and industrial wastes, vehicles, industrial enterprises, cotton gins, construction materials plants, mining wastes, and others.

Pollution of irrigated agro-landscapes, which make up a large part of the Samarkand oasis, and their negative impact on the geoecological environment is inextricably linked with the overuse of mineral fertilizers and high-toxic chemicals. In addition, sources of pollution of agrogeosystems, irrigation facilities, groundwater and surface water include domestic wastewater, water used in the mining industry for washing ore and saturated with trace elements, saline water from collector ditches, etc. [2].

All types of pollutants in the oasis have a negative impact on the natural and 
anthropogenic geosystems of the Samarkand oasis, the environment, atmospheric air, inland waters, soil and vegetation, affecting their ecological status, sanitary and hygienic conditions of urban and agricultural landscapes. led to a violation. In particular, in all types of anthropogenic geosystems that form part of the landscapes of the Samarkand oasis, there are specific local and regional environmental problems. Finding solutions to these problems requires the development of scientifically based measures, each of which has an individual character, and their implementation.

\section{RESULTS AND DISCUSSIONS}

The main part of the Samarkand oasis is agrolandscapes. The composition of agrolandscapes consists of irrigated and spring arable lands, orchards and vineyards, forest strips that protect fields, perennial anthropogenic trees and cultivated pastures.

A large area of Samarkand Oasis landscapes, which had been an irrigation farming center since ancient times, is occupied by cotton plantations, which became a monopoly of farms. In such plantations, failure to comply with the rule of alternating Planting for many years, timely processing of cultivated soils from an agrotechnical point of view, the use of mineral fertilizers and pesticides in order to increase productivity beyond the norm, irrigation of cultivated areas from mineral waters led to the impoverishment, salinity and contamination of agrolandshaft soils with various chemicals. As a result, a number of environmental problems arose as a result of agrolandshafts and environmental pollution[1].

The second chemical factor that constantly poisoned Agrolandshaft Kompleks and caused the environmental situation, which affects the health of people living in the territory of the Oasis, is pesticides. In recent years, instead of the previously used chloroorganic and phosphoric pesticides, in most cases, chlorate magnesium, chlorate calcium, crushed sulfur, copper powder and others from inorganic chemical compounds are used. Due to the greater use of inorganic chemical compounds, even in the composition of irrigated soils, their average content exceeds the permissible norm by 1-2 times. Consequently, irrigated soils are a major producer and an integral part of agrolandshafts, due to the excessive use of mineral fertilizers on them, excessive application of pesticides, as well as noncompliance with the rule of crop rotation, Oasis landscapes may face irreparable geoecological tragedy in the near future[4].

One of the most important components of the Samarkand Anthropoid Oasis landscape, its internal waters, like other components, are contaminated from year to year and cause environmental problems of the waters used in drinking and irrigation. If, as a result of pollution of internal water bodies, first of all, the natural environment is damaged, then, in the second place, along with living organisms, humans, soils and plants are also damaged [3]. Protection of Samarkand Oasis landscapes, preservation of productivity, preservation and rational use of them in the interests of mankind for the future generation is one of the most urgent problems of the present day. Protection of nature is a broad concept, it consists of a system of measureseksex. This complex system is designed to preserve nature in the interests of mankind for the present and future generation, to consciously and purposefully modify it, to recultivate land unsuitable for use, to rational use of natural resources, to prevent pollution of atmospheric air, groundwater and surface 
waters, to restore the ecological balance of the environment, to maintain and increase the productivity of agrolandshafts, to optimization of degradation process, it is made up of a complex of activities such as combating soil erosion and re-salinity of soils that occur on irrigated lands, rational use of Geosystems taking into account the laws of nature [5].

The impact of irrigation erosion, which occurs in irrigated areas, on the productivity of agrolandshafts, which occupy a significant place in the structure of Oasis landscapes, decreases year after year, the desertification of cultural geocomplexes, the poor soil erosion, is enormous. To protect agrolandshafts from such adverse events, it is necessary to carry out activities such as agromelioration, gidromelioration, phytomelioration [1].

It is necessary to take the following measures in order to improve the health of the environment in Samarkand Oasis landscapes, in particular within the framework of landscapes and to optimize the environmental conditions of the Environment: 1.Restoration of a wide green Woody region around the city and agricultural landscapes, constantly improving the health of the microclimate; 2.Organize the construction of waste recycling plants within the scope of Oasis Geosystems, achieve geoecological efficiency and improve the environmental situation of polluted environment; 3.Development of scientificbased measures to prevent the contamination of domestic waters with toxic chemical compounds, various microelements, petroleum products and the increase in the level of mineralization; 4.wide introduction of their application in practice; 5. the development of scientific-based measures for the Prevention of pollution of domestic waters by toxic chemical compounds, various microelements, petroleum products; 6 . theTo organize on scientific basis the rational use of anthropogen geocomplex in order to optimize the geoecological situations that cause the decrease in the productivity of irrigated agrolandshafts, the desertification process that is taking place in them and that are increasingly occurring; 5. To increase the productivity of agrolandshafts and improve the quality of the products grown in agriculture, to organize the use of mineral fertilizers on irrigated soils and cultural crops, pesticides in the allowable standard, the widespread use of organic fertilizers, etc.

\section{CONCLUSION}

Consequently, in order to optimize the environmental conditions that have arisen in Samarkand Oasis landscapes and are developing day by day, and to ensure a high yield, which is stabilized every year in agriculture, to take into account the morphological structure of agrogeocystems, their local natural conditions, to make the right way of exchanging plantations, to use organic and mineral fertilizers in, it is necessary to carry out the specified meliorative measures in a timely manner, to use labor resources for its intended purpose, to properly organize labor. The integrated implementation of this complex of activities will make it possible to improve and stabilize the ecological balance in Oasis Geosystems.

\section{REFERENCES}

1. Abbasov S. B., Samyaev A. K. Modern ecological problems of the Zarafshan River Delta. // International scientific journal Theoretical and Applied Science. - 
Philadelphia, USA. 2020. Size: 81. - P. 636638.

2. Abdulqasimov A.A., Abdurahmonova Yu.H. Geographic basis of optimization of the ecological state of Oasis landscapes / / regional problems of natural geography. Samarkand, 2002. 15-19 b.

3. Meliev B.A. Aerospace in the research of Mediterranean Zarafshan landscapes, / / t. the $f$. $n$ disse use mathematical and Geoinformation techniques.Authoref. Samarkand, 2019. - 41 b.

4. Nigmatov A., Gulmatov R., Rasulov A., Mukhamedov Sh. Sustainable development and its structural indicators (monographs). - Tashkent, 2015. - 120 b.

5. Eshkovvatov B. B., Yarashev K. S. scientific-practical activities of analysis of Plains and landscapes / / natural and scientific journal. Size 3 Number 18,. USA. March 25, 2020. ISSN: 1545-0740; - P. 6062. 